\title{
Pulmonary histoplasmosis presenting with a halo sign on CT in an immunocompetent patient
}

\author{
Histoplasmose pulmonar presente com sinal do halo em TC em um \\ paciente imunocompetente
}

\author{
Graziella Hanna Pereira, Liliane Yuri Almeida, Rosa Shizuda Okubo, Edson Marchiori
}

\section{To the Editor:}

Histoplasmosis is a common endemic mycosis. Although most infections in immunocompetent individuals are self-limiting, some patients develop severe pneumonitis or other types of chronic pulmonary infection. Specific imaging findings depend on the organisms involved, the underlying condition of the patient, and his condition after immune depleting procedures. The disease process in immunocompetent patients is usually limited to a solitary nodule on chest X-rays or CT scans, but enlarged hilar or mediastinal lymph nodes can also be observed. ${ }^{(1)}$ We report here the case of an immunocompetent patient with histoplasmosis who presented with a halo sign on CT.

A 47-year-old man presented with dry cough, chest pain, fatigue, and fever, having started 15 days prior. He reported neither comorbidities nor a contact with environments with mold. The patient was negative for HIV by ELISA. Laboratory tests revealed leukocytosis, elevated C-reactive protein levels ( $33 \mathrm{mg} / \mathrm{L}$ ), and hypertransaminasemia (three-fold higher than the upper limit of normal). CT scanning revealed a pulmonary nodule with a halo sign in his left lower lobe (Figure 1) and left para-hilar lymph nodes. Histological examination of a pulmonary biopsy sample obtained during bronchoscopy showed nonspecific inflammatory alterations. Cultures for mycobacteria and fungi were negative. Serology by counterimmunoelectrophoresis was positive for histoplasmosis.

Treatment was initiated with itraconazole (400 mg/day). After 30 days, a CT scan showed that the size of the nodule was reduced by half.

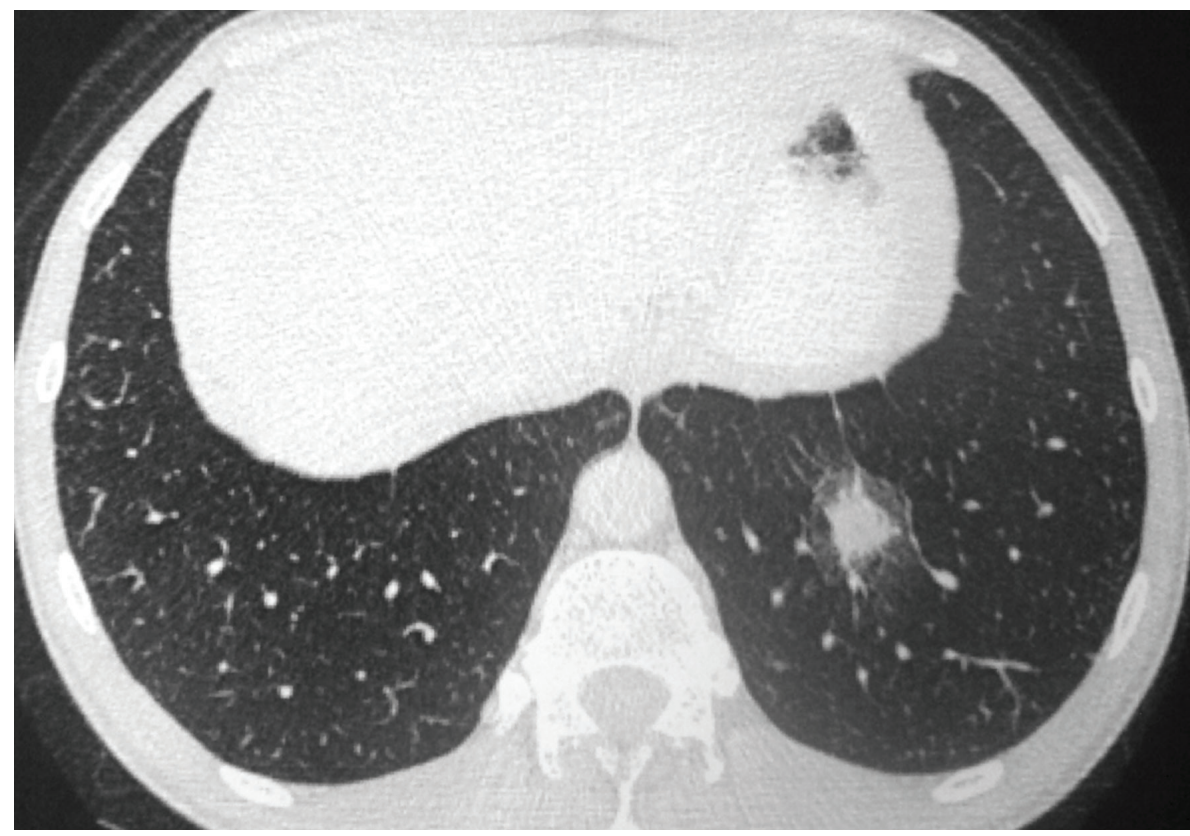

Figure 1 - A CT scan at the level of the lower lobes showing a nodule surrounded by ground-glass attenuation (halo sign) in the left lower lobe. 
The patient showed progressive improvement of clinical symptoms and a reduction of the paraaortic adenopathy. Treatment was maintained for one year, during which the patient remained asymptomatic, the nodule completely disappeared, and the lymphadenopathy resolved. However, histoplasmosis by counterimmunoelectrophoresis remained positive.

We reported the case of an immunocompetent patient who presented with a halo sign and lymphadenopathy caused by histoplasmosis, showing a good clinical response after one year of treatment with itraconazole (400 mg/day). Histoplasma capsulatum is a major endemic human fungal pathogen that can cause a broad variety of clinical presentations, ranging from mild, focal pulmonary disease to life-threatening systemic infections. ${ }^{(1)}$ In one study, open lung biopsies of 155 patients with undiagnosed lung lesions showed that infectious etiologies were responsible for $19 \%$ of the lesions, the most common diagnosis in this group being histoplasmosis $(41 \%)$. $^{(2)}$

The halo sign is characterized by a ground-glass opacity surrounding a nodule, mass, or round area of consolidation. ${ }^{(3)}$ This sign is frequently an early indicator of invasive pulmonary aspergillosis in immunocompromised patients, ${ }^{(4)}$ but it might also indicate other invasive fungal diseases.

Our patient required treatment with high doses of itraconazole for one year. Azoles, such as itraconazole and voriconazole, and amphotericin B have significant activity against H. capsulatum. However, approximately $10 \%$ of the patients hospitalized due to histoplasmosis die, ${ }^{(5)}$ despite the lack of antifungal resistance among recovered isolates. ${ }^{(6)}$

In conclusion, a halo sign on CT might indicate active histoplasmosis, which may require long-term treatment, even in immunocompetent patients.

\section{Graziella Hanna Pereira Infectious Disease Specialist, Hospital Nipo-Brasileiro de São Paulo, São Paulo, Brazil}

Liliane Yuri Almeida

\author{
Pulmonologist, Hospital Nipo-Brasileiro
}

de São Paulo, São Paulo, Brazil

Rosa Shizuda Okubo

Radiologist, Hospital Nipo-Brasileiro de

São Paulo, São Paulo, Brazil

\author{
Edson Marchiori
}

Radiologist, Federal University of Rio de Janeiro, Rio de Janeiro, Brazil

\section{References}

1. Chong S, Lee KS, Yi CA, Chung MJ, Kim TS, Han J. Pulmonary fungal infection: imaging findings in immunocompetent and immunocompromised patients. Eur J Radiol. 2006;59(3):371-83. http://dx.doi.org/10.1016/j. ejrad.2006.04.017 PMid:16725293

2. Georgiadou SP, Sampsonas FL, Rice D, Granger JM, Swisher S, Kontoyiannis DP. Open-lung biopsy in patients with undiagnosed lung lesions referred at a tertiary cancer center is safe and reveals noncancerous, noninfectious entities as the most common diagnoses. Eur J Clin Microbiol Infect Dis. 2013;32(1):101-5. http://dx.doi. org/10.1007/s10096-012-1720-9 PMid:22895891

3. Silva $\mathrm{Cl}$, Marchiori E, Souza Júnior AS, Müller NL; Comissão de Imagem da Sociedade Brasileira de Pneumologia e Tisiologia. Illustrated Brazilian consensus of terms and fundamental patterns in chest CT scans. J Bras Pneumol. 2010;36(1):99-123. http://dx.doi.org/10.1590/S180637132010000100016 PMid:20209314

4. Greene RE, Schlamm HT, Oestmann JW, Stark P, Durand C, Lortholary 0 , et al. lmaging findings in acute invasive pulmonary aspergillosis: clinical significance of the halo sign. Clin Infect Dis. 2007;44(3):373-9. http://dx.doi. org/10.1086/509917 PMid:17205443

5. Nosanchuk JD, Zancopé-Oliveira RM, Hamilton AJ, Guimarães AJ. Antibody therapy for histoplasmosis. Front Microbiol. 2012;3:21. http://dx.doi.org/10.3389/ fmicb.2012.00021 PMid:22347215 PMCid:3270318

6. Brilhante RS, Fechine MA, Mesquita JR, Cordeiro RA, Rocha MF, Monteiro AJ, et al. Histoplasmosis in HIV-positive patients in Ceará, Brazil: clinical-laboratory aspects and in vitro antifungal susceptibility of Histoplasma capsulatum isolates. Trans R Soc Trop Med Hyg. 2012;106(8):484-8. http://dx.doi.org/10.1016/j. trstmh.2012.05.003 PMid:22703696 